\title{
Tourism and Ecological Protection in the Philippines
}

\author{
Lili XU ${ }^{1,}$, , Peng XU 2,b \\ ${ }^{1}$ The Southern Base of Confucius Institute Headquarters, Xiamen 361005, China \\ ${ }^{2}$ South China Sea Institute, Xiamen University, Xiamen 361005, China \\ alynch206@163.com, b13285927856@163.com
}

Keywords: the Philippines, tourism resource, ecological protection

Abstract. The Philippines has a diversely beautiful topography which is an awe-inspiring combination of mainland and thousands of smaller islands. But as to the development of tourism, there is still a large gap between the Philippines and other Southeast Asian countries with highly developed tourism. However, the Philippines takes "original ecology" as a unique way to attract tourists, which provides a solution to alleviate the fund pressure of the construction of tourism facilities, better meets the ecological protection requirements of the international community and provides a new development idea for other countries with less advanced tourism.

\section{Introduction}

The Philippines is an archipelagic state which consists of more than 7000 islands, known as the "Country of Thousand Islands" in Southeast Asia. As its location on the Pacific Ring of Fire and close to the equator makes the Philippines prone to earthquakes and typhoons, but also endows it with abundant natural resources and some of the world's greatest biodiversity. The Philippines pays more attention on its own environmental resources. By 2012, 240 protected areas have been built in the Philippines, covering $13.5 \%$ of the land area $\left(40587 \mathrm{~km}^{2}\right)$ and $1.5 \%$ of territorial waters ${ }^{[1]}$, including national parks, landscapes, seascapes, wildlife sanctuaries and small watersheds and more.

\section{Tourism Resource in the Philippines}

As an archipelagic country, the Philippines has a wealth of land and marine tourism resources. Its landforms are complex and varied, including mountains, plains, plateaus, canyons, lakes, rivers, volcanoes, grasslands, forests and so on. Two thirds of the Philippines' are mountainous areas with narrow coastal plains. The coastline of the Philippines is about $36289 \mathrm{~km}$ long with $770 \mathrm{~km}^{2}$ waters.It has many good natural harbors, among which Manila Bay is one of the best in the world. ${ }^{[2]}$

The Philippines has a large number of ethnic groups with different cultures. Negritos are believed to be the earliest inhabitants. Later, the immigration of the Austronesians brought in Malay culture in the archipelago. And with the introduction of religion and trade development, people in the Philippines were also influenced by Indian, Chinese and Islamic cultures.

\section{Approaches to Develop Land Tourism Resources Combined with Ecological Conservation—_-Take the Rice Terraces of the Philippine Cordilleras As an Example}

The Rice Terraces of the Philippine Cordilleras were inscribed on the UNESCO World Heritage List in 1995. Mountain terraces, together with virgin forests at higher elevations, plantations, living communities and rivers in the valley, form a self-sufficient ecological system. The terraced fields harvest water from the forests on the mountain top. The plantations and villages in between provide the living environment for human beings, reducing human's impact on forests. ${ }^{[3]}$

However, tourism development endangered the ecosystem here. Over-developed tourism led to extensive deforestation. Trees were cut to give way to building roads for tourism, damaging trees's ability to holding water. Moreover, many buildings were built in the villages without unified planning and design. What mentioned above destroyed the ecosystem and shrank the areas of terraced fields. 
Meanwhile, the immigration of workforce to urban cities and global climate change also posed negative impacts on the maintenance of the terraces.As a result, the Rice Terraces here have been inscribed in the List of World Heritage in Danger in 2001. ${ }^{[4]}$

The Provincial Government and agencies concerned tried their best to establish programs to ensure landscape restoration and conservation through continuous physical rehabilitation of deteriorated areas, including the revival of traditional practices that addresses cultural degeneration. Sustained efforts have been carried out by the government and relevant national agencies to ensure conservation and management. Measures include the enactment of national government policies and laws for the preservation of natural resources, the adoption of guidelines for conservation, and for procedures for Environmental Impact Assessments and infrastructure for the implementation of major projects. Management agencies at the provincial and municipal levels also pay more attention to coordinate with the rice terraces owners' organizations. ${ }^{[5]}$

Good news is that, in 2012, UNESCO has removed the Rice Terraces from the list of sites in danger in recognition of the success of the Philippines in improving its conservation.

\section{Approaches to Develop Marine Tourism Resources Combined with Ecological Conservation_— Take Olango Group of Islands as an Example}

Brief introduction to the Olango Groups of Island. The Olango Group of Islands(OGI) consists of seven islands, located in the east of Cebu province. It has a total land area of approximately 1,030 hectares. ${ }^{[6]}$ OGI has a diverse coastal ecosystem consisting of extensive coralline sandflats, mangroves, seagrass beds and offshore coral reefs. It is one of the seven best-known flyways in the world for migrating birds. There are 97 species of birds in Olango, 48 of which are migratory species. ${ }^{[7]}$ Meanwhile, Olango hosts more than half of migratory birds that use the East-Asian Austral-Asian flyways, up to $62.23 \% .{ }^{[8]} \mathrm{OGI}$ is also a famous diving resort with one of the deepest wall diving in the world. Baring is along the North-Western side of the island and the wall starts at $20 \mathrm{~m}$ and ends down to about $73 \mathrm{~m}$ before disappearing on a gradual slope. ${ }^{\left[{ }^{9]}\right.}$ It is the best place to watch many kinds of fish, such as grey reef sharks, tuna, barracuda, snappers, jacks and so on.

The Government's Management Measures to Promote Ecotourism on the Olango Island.

To Set Up Protected Areas and Promote Eco-tourism Programs. Olango Island Wildlife Sanctuary (OIWS) was proclaimed as a protected area by virtue of Presidential Proclamation 903 and was recognized as the 1st RAMSAR SITE (Wetland of International Importance especially as Waterfowl Habitat) in the Philippines during the RAMSAR Convention in RAMSAR City of Iran for the Preservation and Protection of Wetlands of International Importance on Nov. 8, 1994. In addition, Olango Island is also one of the Important Bird Area (IBA) in the Philippines. ${ }^{[10]}$

In recent years, the government is actively encouraging Olango tourism development to promote local economy. Therefore, the conflict between ecological protection and tourism is inevitable, such as the destruction of mangrove areas, which are important habitats and places for migrant birds to prey. Some fishery conservation zones are also destroyed. In order to alleviate the conflict, the government is actively promoting the eco-tourism plan to adopt various measures for the development of local tourism under the premise of realizing the protection of biodiversity.

Management Strategies. Management agencies try to divide different management zones in the sanctuary according to their features and categorize management approaches, improve tourism infrastructure and facilities, upgrade scientific research and monitoring, establish a biodiversity monitoring system, rehabilitate mangrove planting on degraded mangrove areas caused by indiscriminate cutting, ensure the enforcement of the Environmental Laws and strengthen patrolling and the management of tourists, improve the income of local inhabitants, carry out more cooperation with other governmental and non-governmental organizations, establish various types of funds, seek training for the staff to upgrade knowledge and skills in the management of the sanctuary, and evaluate the operation and management of the sanctuary annually. ${ }^{[11]}$ 
It has been proved that the management of Olango Island is a success. It not only improves the island's economy, but also achieves the goal of biodiversity conservation. Its experience is worth to be shared.

\section{Successful Experience of Other Countries and Suggestions to the Philippines}

\section{Successful Experience of Other Countries.}

Seychelles. Seychelles is an archipelago country in the Indian Ocean. It is made up of 115 islands. Fisheries and ocean-based tourism are pillar industries of this country. In recent years, many problems, such as sea level rise, coral bleaching and seawater acidifications caused by climate change, have seriously affected Seychelles' natural environment and ecological system. However, as a biodiversity hotspot, Seychelles finds some special ways to ensure a balanced development of the economy and environmental protection. Its government has reached an agreement with the United Nations Environment Program (UNEP), in which announcing its intention to expand its natural reserve from $0.04 \%$ of the exclusive economic zone (EEZ) in 2014 to $30 \%$ in 2020 , an area of $400,000 \mathrm{~km}^{2}$. Moreover, another unique project is also underway. It links a restructuring of some of the island nation's international debt with a financial mechanism to support adaptation to climate change, namely through improved marine and coastal ecosystem management. The debt restructuring, facilitated by The Nature Conservancy(TNC) with the involvement of the Paris Club of creditor nations and South Africa, includes using private investment to buy back US \$30 million of Seychelles debt at a discounted rate. In turn, the Seychelles government agrees to complete a legislated marine spatial plan, create the Seychelles Conservation and Climate Adaptation Trust to fund implementation of the plan as well as other conservation and climate adaptation projects. ${ }^{[12]}$

The way that Seychelles use the nature reserves and the protection of biodiversity as "financing products" to exchange for financial support from international organizations is effectively alleviate contradictions between economic development and ecological protection.

Jamaica. Jamaica is the fourth-largest island country in the Caribbean, by area. ${ }^{[13]}$ It is situated in the northwest of the Caribbean Sea and has a 1200-kilometer coastline. Tourism, mining, agriculture and emerging information technology services are pillars industries here.Service industry centered on tourism accounts for more than $60 \%$ of Jamaican's GDP.

In recent years, Jamaica's heavy dependence on the energy supply of imported oil has been challenged by the volatility of world oil prices, the shortage of government finance and the climate change. In order to solve the problem, the Jamaican government is paying more and more attention to the usage of renewable energy. The main way they choose is to introduce international financial and technical support.

During the recent completed projects in Jamaica which have helped communities across the island to reduce their vulnerability to natural hazards and climate change, Jamaica received totally over CAD $\$ 175,000$ fund support, with CAD $\$ 80,661$ coming from the Government of Canada. ${ }^{[14]}$ Jamaica also used the World Bank's financial support to complete the feasibility study on the implementation of small hydropower projects across the country. In addition, Jamaica's renewable energy project and counter climate change project have also benefited from funds from the Green Climate Fund(GCF). ${ }^{[15]}$ But such measures have high requirements on the local environmental characteristics. So Jamaica's experience can only apply to those countries which natural environment has a similar special protection value, such as the Philippines.

Suggestions on Improving the Ecological Tourism in the Philippines. The Philippines is one of the biodiversity conservation hotspots in the world with unique land and marine resources. Its government and public have gradually paid more attention to ecological environmental protection and ecotourism. However, due to the constraints of funds and scientific research, and lack of awareness of ecological protection, the effects of some measures carried out and the implementation of related regulations are far less than previously expected and it is also hard to sustain. Therefore, it is of great significance to enhance the financing capacity of local 
ecological projects, expand the channels of capital inflow, strengthen the scientific research support, improve the quality of ecotourism, introduce more suitable development model and improve the cultivation of public ecological consciousness for further development of local ecotourism.

To Promote the Construction of National Parks and Marine Nature Reserves by Seeking International Financial Support. Seychelles' experience is a good example for the Philippines. The Philippine government and local organizations can consider seeking financial support from international funds to protect ecosystems and biodiversity. This can alleviate the shortage of government tourism construction funds as well as give a better protection to ecological system and natural environment. It is also possible to improve the recognition of these regions in the world.

To Establish a Biological Resources Database and Gradually Improve It. One of the most popular ecotourism items in the Philippines is diving. As we mentioned before, there are a lot of different places suitable for diving here. Many divers' interests in diving here is to watch and research the diversified creatures in the underwater world. The Philippines should seize this opportunity to deepen the research on marine organism, and promote the construction of island species resources database. First of all, a database like this can help the local diving instructors to become more familiar with local sea creatures which they can show to the visitors. This can thereby enhance the competitiveness of diving places here. Second, it can also enhance the public's awareness of biodiversity protection, prevent the loss of island species and truly achieve the goal of biodiversity conservation. We can also take Threatened Island Biodiversity Database set up by Small Island Developing States in 2013 as a reference, to promote the data sharing and research cooperation in the field of marine research and islands development between the Philippines and other countries. ${ }^{[16]}$

To Strengthen Supervision and Inspection on the Natural Ecological Environment. Due to global climate change and human destruction of nature, the urgency to strengthen the monitor of natural environment is increasing, especially for mangrove area and coral reef. As the situation of $70 \%$ coral reef in the Philippines having been deteriorated, it is urgent to strengthen enviromental monitoring here. On the basis of previous work on ecology and environmental protection, the Philippines can also use Jamaica's experience as a reference to seek financial and technical support from relevant agencies and international organizations. For example, they can apply for funding and technical support for renewable energy from agencies like UNEP and GCF.

To Seek Educational Support. In addition to getting technical and financial support from other countries and relevant organizations, the Philippines can also consider to provide research resources in exchange for educational assistance. The platform of Lifelong Learning for Energy, Access, Security and Efficiency in African and Pacific Small Island Developing States (L3EAP) created in 2014 is a good example for the Philippines. ${ }^{[17]}$ L3EAP learning module addresses distinctive knowledge and technology needs and demands of developing countries in Africa, Caribbean and Pacific Group of States in the field of sustainable energy production, renewable energy production, energy efficiency and energy security. ${ }^{[18]}$ It also addresses a topic that is most relevant for the local labor market and socio-economic development in general. As to the Philippines, it is beneficial to consider taking this model as a reference, cooperating with countries with successful eco-conservation experience and successful coastal eco-tourism development models, to provide a research base and resources for excellent research teams and technical organizations in the world, to supply public learning channels of ecological knowledge and the information of market development and to develop their own scientists and experts on the ecology and eco-tourism.

\section{The Enlightenment for Other Countries by the Experience of the Philippine}

Compared with developed countries, the Philippines is more restricted in the investment in tourist resources due to its financial and technological constraints. As a result, the government decided to attract tourists with"original ecology", which can save the investment in the infrastructure as well as conform to the international community's initiative to protect biodiversity and ecological conservation. The Philippines can get more favorable conditions for its eco-tourism development if it 
can acquire supports of funds, technology and education from the international community to secure its biodiversity under climate change as other countries did. From the perspective of ecological protection, this is a good example for countries that lack fund but with rich tourism resources. When referring to the experience of the Philippines, the following points should be noticed:

To Build Reserves with Different Functions and Treat Them with Different Management Modes Correspondingly. For those with rich resources and multiple landforms, we should employ diverse management measures to maximize the overall interests, i.e., adjusting measures to local conditions and setting different function zones according to their ecological characteristics. For example, areas with high ecological protection value can be designated as "strictly protected areas". Activities except scientific research are not permitted here, such as sightseeing. For a region with less ecological but higher entertainment value, it can be identified as an ecological tourist area, where tourism, swimming, education and entertainment activities can be developed. In the sustainable reserves, the inhabitants are allowed to farm, develop resort facilities or sell tourist souvenirs without harming the biodiversity. Through the above measures, the coordinated development of biodiversity and local economy can thus be maximized.

To Coordinate the Local Ecological Protection and Economic Development. An important feature of Philippine eco-tourism is to make local residents and fishing villages as important parts of tourism, to bring income for local residents and develop local economy. At present, a certain scale of local residents live in nature reserves in many developing countries. Inevitably, they will have certain impacts on local natural ecology while maintaining traditional habits. Under such circumstances, we should take some measures to strengthen and expand local tourism by setting an ecotourism-oriented economic mode, improving the utilization ratio of ecological environment, raising public awareness of ecological protection and skills.

To Plan the Implementation Mechanism for Relevant Ecological Laws and Regulations. In 1998, the Philippines issued the National Ecological Tourism Law and established the national ecotourism commission (NEDC) to provide operational guidelines for the development of ecotourism in the Philippines. In the process of implementation, the communication between relevant central law enforcement agencies and local governments, and the cooperative mechanism among the government, associations and enterprise were established. Meanwhile, law enforcement officials are appointed to strengthen the patrol and supervision of relevant nature reserves, and build up significant protection signs in related areas. The laws and regulations on ecological protection and economic development are also adapting to the changing situation.

Be People-oriented, and Pay Attention to Local Residents' Participation. In the development of eco-tourism in the Philippines, the local residents are more direct participants and beneficiaries. The Philippines' Palawan Island was crowned for two consecutive years in the Top 10 Island of the World in 2017, according to Travel\&Leisure, a leading travel magazine. The successful eco-tourism image here is the result of collective efforts. Since 1992, the province started environmental protection, the government and non-governmental organizations and Palawan residents have participated collectively in the development and protection of local resources through reducing human interference, developing environmental protection travel routes and products (such as diving, dolphin-watching). It is a successful example for other tourist attractions. Other countries and regions should also establish mechanism on local residents' full participation in the development of local eco-tourism. For example, the residential area can be developed as a special resort for accommodation, catering, or souvenir sales, and the local residents will be trained as tourism practitioners and managers to expand business opportunities for local residents. Local residents can be trained to be guides or staff majoring in tourism management. They can also participate in the development of special tourist routes and products, such as leading visitors to watch sea turtles, dolphins, whales and birds, and teaching diving, to share the benefits of island tourism. 


\section{Conclusions}

The Philippines is an archipelagic country with abundant natural resources and historic sites. Its development in ecological tourism conforms to people's pursuit to get closer to the nature, as well as complies with the requirements of the international community to protect ecological environment and biodiversity. The combination of appropriate planning and development is the Philippines' important way to maintain characteristics and create regional benefits. Its achievements and challenges during the process of ecotourism development will be a good reference for those tourist countries with similar environmental conditions.

\section{Acknowledgements}

This work was financially supported by the Education and Research Projects for Young and Middle-aged Teachers in Fujian, "Study on the Factors Influencing the Local communication of Chinese in Malaysia",Fujian Education Department (JAS160027).

\section{References}

[1] Anon. 2012. Action plan for implementing the Convention on Biological Diversity's Programme of Work on Protected.www.cbd.int/database/attachment/?id=1659 [2012-5 -31/2018-8-7].

[2] Information on Wikipedia.https://en.wikipedia.org/wiki/Philippines\#cite_note-climate-297 [2010-4-28/2017-8-10].

[3] Rice Terraces of the Philippine Cordilleras, Wikipedia.https://en.wikipedia.org/wiki/Rice_ Terraces_of_the_Philippine_Cordilleras [2012-6/2017-8-10].

[4] [5] Huijun Hou, Dan Luo, Ming Zhao. Reconstruction of landscape pattern on terraces based on the theory of ecological restoration and culture regression for mountain rice terraces in the Philippines Cordillera region. Acta Ecologica Sinica,2016,36( 1) : 148-155.(In Chinese)

[6] Information on Wikipedia. https://en.wikipedia.org/wiki/Olango_Island_ Group\#cite _note-One-3 [2017-8-10].

[7] Information on Wikipedia,https://en.wikipedia.org/wiki/Olango_Island_Group\#cite _note-Society-11[2017-8-10].

[8][10][11] Reginaldo G. Bueno. Eco-tourism and Biodiversity Conservation and Protection Management of Olango Island Wildlife Sanctuary. http://www.olangowildlifesanctuary.org/ Olangopaper1.pdf [2017-8-10].

[9] Asia Dive Site. http://www.asiadivesite.com/philippines-dive-sites/mactan/ olango-island.php [2017-8-10].

[12] MPA News staff.Seychelles project combines ocean planning, climate change adaptation, and debt restructure.2016. https://mpanews.openchannels.org/news/mpa-news/seychelles-project -combines-ocean-planning-climate-change-adaptation-and-debt[2016-2-25/2017-8-10].

[13] Information on Wikipedia, https://en.wikipedia.org/wiki/Jamaica\#cite_note-8[2017-8-10].

[14] Carribbean Climate . https://caribbeanclimateblog.com/2017/02/21/jamaican-communities -better-able-to- address-emergencies-and-climate-change-with-canadian-support/[2017-8-10].

[15]Emiliano Bellini.2017.Jamaica targets $\$ 300$ million renewable energy investments. https://www.pv-magazine.com/2017/04/28/jamaica-targets-300-million-renewable-energy -investments/ [2017-4-28/2017-8-10].

[16] Yuncheng Deng.2017.The urgency of island biodiversity conservation-A brief Introduction of Threatened Island Biodiversity Database. China Ocean News.http://epaper.oceanol.com /shtml/zghyb/20170104/64639.shtml[2017-1-4/2018-8-10].(In Chinese)

[17] Yuncheng Deng.2017. Education - an aid to Small Island Developing States.China Ocean News. http://epaper.oceanol.com/shtml/zghyb/20170113/64802.shtml [2017-1-13] (In Chinese)

[18] Franziska Wolf, Deisi V. Becker, Walter Leal et al. 2016.Sustainable energy generation and use in SIDS and beyond-introducing the L3EAP online learning approach. Brazilian Journal of 
Science and Technology2016 3:2:1-2. https://bjst-journal.springeropen.com/articles /10.1186/s40552-016-0021-8[2016-3-7/2017-8-10]. 